\title{
Comparative Anti-mycobacterial Activity on Lowenstein-Jensen Slants of Selected Medicinal Plants Used in the Congolese Pharmacopeia
}

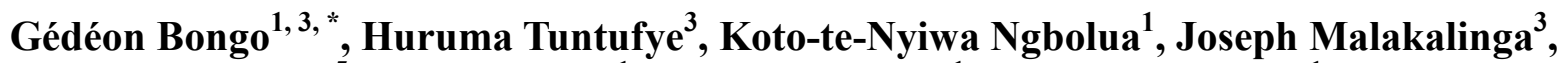 \\ Tshiama Claudine ${ }^{5}$, Aaron Pambu ${ }^{1}$, Fabrice Mwanza ${ }^{1}$, Clément Mbadiko ${ }^{1}$, Gisèle Makengo ${ }^{1}$, \\ Jeff Iteku', Dorothée Tshilanda ${ }^{2}$, Pius Mpiana ${ }^{2}$, Théophile Mbemba ${ }^{1}$, Rudovick Kazwala ${ }^{4}$ \\ ${ }^{1}$ Department of Biology, Faculty of Science, Kinshasa, Democratic Republic of the Congo \\ ${ }^{2}$ Department of Chemistry, Faculty of Science, Kinshasa, Democratic Republic of the Congo \\ ${ }^{3}$ Department of Veterinary Microbiology, Parasitology and Immunology, College of Veterinary Medicine and Biomedical Sciences, Sokoine \\ University of Agriculture, Morogoro, Tanzania \\ ${ }^{4}$ Department of Veterinary Medicine and Public Health, College of Veterinary Medicine and Biomedical Sciences, Sokoine University of \\ Agriculture, Morogoro, Tanzania \\ ${ }^{5}$ Enseignement et Administration en Soins Infirmiers, Section Sciences Infirmières, Institut Supérieur des Techniques Médicales, Kinshasa, \\ Democratic Republic of the Congo
}

Email address:

gedeonbongo@gmail.com (G. Bongo)

\section{To cite this article:}

Gédéon Bongo, Huruma Tuntufye, Koto-te-Nyiwa Ngbolua, Joseph Malakalinga, Tshiama Claudine, Aaron Pambu, Fabrice Mwanza, Clément Mbadiko, Gisèle Makengo, Dorothée Tshilanda, Pius Mpiana, Théophile Mbemba, Rudovick Kazwala. Comparative Antimycobacterial Activity on Lowenstein-Jensen Slants of Selected Medicinal Plants Used in the Congolese Pharmacopeia. Journal of Diseases and Medicinal Plants. Vol. 3, No. 5, 2017, pp. 88-96. doi: 10.11648/j.jdmp.20170305.12

Received: October 6, 2017; Accepted: October 28, 2017; Published: November 30, 2017

\begin{abstract}
Tuberculosis is an infectious disease that kills approximately three million people annually worldwide. The emergence of multidrug resistant, extensively drug resistant and lengthy therapy reduces the patient compliance and therefore comprises control strategies. In this study, the leaves of Terminalia ivorensis, Carapa procera, Fagara macrophylla, Anacardium occidentale, Ficus spp. and Drepanoalpha $®$ (a polyherbal medicine to relieve sickle cell anaemia) were extracted with petroleum ether, ethyl acetate and methanol in order to screen potential bioactive compounds in different extracts and to assess their anti-mycobacterial activity against Mycobacterium tuberculosis H37Rv and Mycobacterium tuberculosis spp. on Lowenstein-Jensen medium using a qualitative approach. The activity was determined as to whether there was growth or not. It was shown that only the methanolic extract displayed a good activity on both strains than the petroleum ether and ethyl acetate extracts. The presence of phytochemicals in plants such as alkaloids, flavonoids, tannins, saponins, anthocyanins and quinones known to be of medicinal importance pointed out a possible source for anti-mycobacterial agents to address the problem of multidrug resistance. The in vitro findings of this study provide a partial support for the use of these plants in the control of various infectious diseases as lead to drug discovery and should be reiterated and recommended for a clinical trial using an animal model.
\end{abstract}

Keywords: Tuberculosis, Lowenstein Jensen, Anti-mycobacterial Activity, Phytochemicals, Medicinal Plants

\section{Introduction}

Being principally a disease of poverty, Tuberculosis (TB) is one of the oldest leading causes of morbidity and mortality and remains one of the deadliest communicable diseases in human history globally [1] [2]. It is caused by Mycobacterium tuberculosis (M. tuberculosis) and is an important public health concern [3-5]. The global mortality 
rate stands at two million deaths per year with one third of the world's population infected with TB [6]. It is estimated that 9.2 million new cases are diagnosed each year and the disease was declared as a global emergency since 1993 by the World Health Organization (WHO) [1] [6-8]. The emergence of drug resistant strains of $M$. tuberculosis is one of the major reasons contributing to the rise of global incidence of TB since 1980 and it is now a threat to TB control program in many countries [12] [13]. More than 420 000 TB cases worldwide are due to Multi-Drug Resistant (MDR) and Extensively-Drug Resistant (XDR) strains of $M$. tuberculosis; 40000 of these occur in Africa [6][14]. Africa has the largest number of people co-infected with Human Immunodeficiency Virus/ Acquired Immunodeficiency Syndrome (HIV/AIDS) and TB. Thus, HIV is the single most important factor behind Africa's TB re-emergence [15] [16]. In Low-Income countries like the Democratic Republic of the Congo (DRC), TB constitutes a challenge with an estimated incidence smear over 150 cases per 100000 inhabitants where the collapse of health system and the re-emergence of TB as well other infectious diseases are due to the civil unrest [9]. DRC is one of the 22 most affected countries in the world ranking at the $5^{\text {th }}$ place in Africa and $11^{\text {th }}$ in the world [9-11]. Treatment of TB patients co-infected with HIV/AIDS has been associated with treatment failures, relapses, and acquires drug resistance in addition to drug interactions that increase the risk of toxicity. Thus, responding to drug-resistant tuberculosis is really one of the most profound challenges that the global health is facing [16] [17]. Medicinal plants have been used since times immemorial and in Africa, traditional medicine is of great value and more than $70 \%$ of the people refer to traditional healers concerning health issues [18] [19]. The medicinal value of these plants lies in some chemical substances or secondary metabolites such as alkaloids, flavonoids, lignans, fatty acids, polyphenols, quinones and others that produce a definite physiological action on the human body [20]. In laboratory settings, plant extracts have been shown to have a variety of pharmacological effects including antiinflammatory, vasodilatory, antimicrobial, anticonvulsant, sedative and antipyretic effects [21]. The main objective of this study was to assess the in vitro anti-mycobacterial effect of various extracts (Petroleum ether, Ethyl acetate and methanol solvents) of Terminalia ivorensis, Carapa procera, Fagara macrophylla, Anacardium occidentale, Ficus spp. and Drepanoalpha ${ }^{\circledR}$ using Lowenstein- Jensen (LJ) medium.

\section{Material and Methods}

\subsection{Study Design}

This study was an experimental study in which selected Congolese plants namely the leaves of $T$. ivorensis, $C$. procera, F. macrophylla, A. occidentale, Ficus spp. and Drepanoalpha ${ }^{\circledR}$ (a polyherbal medicine used to relieve sickle cell aneamia) were used. Crude extracts were then prepared and tested in-vitro on M. tuberculosis H37Rv (slow growth) and M. tuberculosis spp. (fast growth) that were obtained from NIMR (National Institute for Medical Research) in Dares-Salaam, Tanzania.

\subsection{Plant Collection and Identification}

Selected plant species were collected from Gbadolite, Nord-Ubangi province in DRC during the dry season between July and August 2014. These plants were authenticated at the department of Biology, Faculty of Sciences, University of Kinshasa and kept in room temperature until use. Thus, the voucher specimens were collected and kept at the Herbarium of the Faculty of Sciences, University of Kinshasa to help for the confirmation of plant identity.

\subsection{Extract Preparation}

Powders from dried plants were defatted by soaking in petroleum ether $(1: 10, \mathrm{w} / \mathrm{v})$. The defatted powder was serially extracted by progressively soaking in chloroform, ethyl acetate and methanol to increase solvent polarity with occasional shaking. Whatman's filter paper was used for filtering to obtain the crude extract. The obtained crude solution was then concentrated to a minimum volume by a rotary evaporator at $40^{\circ} \mathrm{C}$ under reduced pressure. Drying, extraction and concentration of extracts were carried out in the Natural Products laboratory, Department of Chemistry and Industries, Faculty of Sciences, University of Kinshasa, Kinshasa, DRC. These extracts were sent to the College of Veterinary Medicine and Biomedical Sciences, Sokoine University of Agriculture to assess their anti-mycobacterial activity.

\subsubsection{Testing of Drug Sensitivity and Anti-mycobacterial Activity of the Extracts Using Proportional Method}

All the procedures were as by the protocol by Bunalema [12] and Mariita [22] with slight modifications. The two isolates $M$. tuberculosis $\mathrm{H} 37 \mathrm{Rv}$ and M. tuberculosis spp. were sub-cultured in LJ medium for 3 weeks and 4 weeks respectively. The extracts were then dissolved in Dimethyl sulfoxide (DMSO) to get the desired final concentrations of $20 \mu \mathrm{g} / \mathrm{mL}$ and $50 \mu \mathrm{g} / \mathrm{mL}$ and were added to the medium (until the tube is half full) before being heated at $85^{\circ} \mathrm{C}$ for 45 minutes in a slanting position in an inspissator (DFT Classic brand) and made ready for use. The prepared medium tubes were cooled at room temperature for 24 hours before use to avoid contamination [22]. Tubes containing the medium were inoculated with strains of Mycobacteria. A stock solution of $2.0 \mathrm{mg} / \mathrm{mL}$ of isoniazid, rifampicin and Ethambutol was prepared separately. Isoniazid was used as positive control, while DMSO was used as negative control.

The two isolates of Mycobacteria were prepared for antimicrobial susceptibility testing using proportion method which enables precise estimation of the proportion of mutants resistant to a given drug and indicates an average sensitivity of the strain. Using a $3 \mathrm{~mm}$ internal diameter wire loop, about $4 \mathrm{mg}$ fresh culture was scraped from LJ medium into in one $\mathrm{mL}$ of Middlebrook $7 \mathrm{H} 9$ broth containing tween 80 in a glass 
bottle (bijou) with five glass beads and vortexed for about 30 seconds to homogenize. The suspension was made up to 4 $\mathrm{mL}$ volume by adding $3.5 \mathrm{~mL}$ sterile distilled water and allowed to settle for about $30 \mathrm{~min}$ before gently aspirating the upper portion into a fresh bijou bottle to get the suspension. Later, the suspension was further diluted to obtain the turbidity of $0.5 \mathrm{McFarland}$ standard turbidity equivalent to $10^{8} \mathrm{cfu}$ using a spectrophotometer (GENESYS 10S brand) [12] [22]. Bacterial suspension was inoculated into extractfree and extract-containing $\mathrm{LJ}$ slopes and incubated at $37^{\circ} \mathrm{C}$. Growth was recorded weekly (for 8 weeks) as: + for high growth, \pm moderate growth and - for no growth. The cultured tubes were examined visually and sample tubes showing less growth (moderate growth) than negative control tubes were considered to be inhibitory. All the experiments were carried out in duplicate due to the slow growth of Mycobacterium. The anti-mycobacterial activity test was carried out in the laboratory of Microbiology, College of Veterinary Medicine and Biomedical Sciences, Sokoine University of Agriculture, Tanzania.

\subsubsection{Phytochemical Screening}

The phytochemical screening was carried out according to the standard techniques [20] [23].

\section{Results and Discussion}

\subsection{Results}

\subsubsection{Anti-mycobacterial Activity of Extracts}

The trend of growth in LJ slants is shown in Figures 1 and 2 below.

Examining tubes visually, some sample tubes showed growth at concentrations of $20 \mu \mathrm{g} / \mathrm{mL}$ and $50 \mu \mathrm{g} / \mathrm{mL}$ for most of the extracts. We did not perform any quantitative analysis. (figures 1 and 2).

The anti-mycobacterial activity of different extracts using LJ medium is shown in tables 1, 2 and 3. The growth was observed in the negative control because it shows if the experiment worked or not. Thus, the absence of growth means inhibition of the bacteria by bioactive compounds and the growth shows resistance.

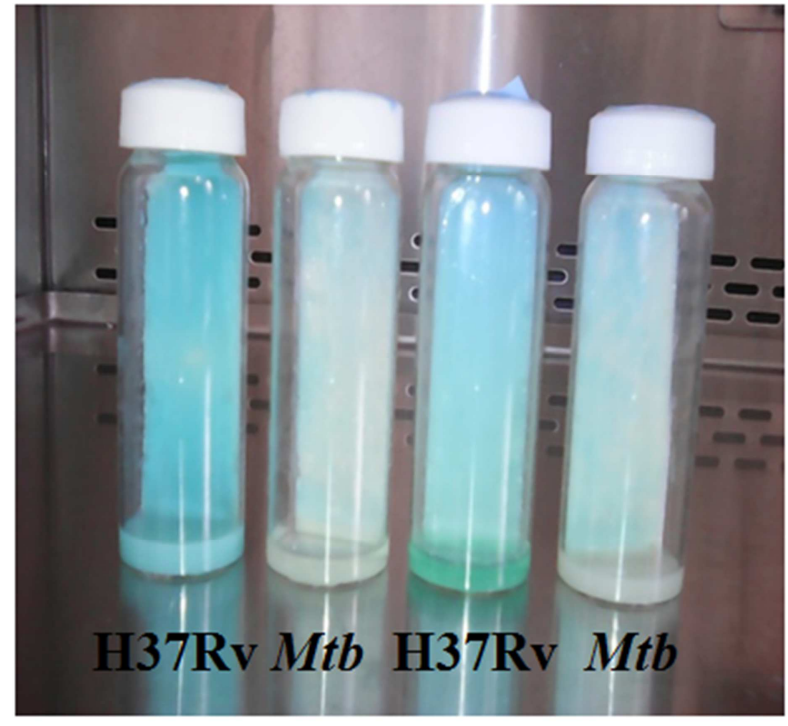

Figure 1. Tubes containing LJ showing growth and inhibition of growth of H37Rv and Mtb. From left to right: Drepanoalpha ${ }^{\circledR}(-)$, T. ivorensis (+), C. procera (-) and Drepanoalpha ${ }^{\circledR}(+)$. The white color on the medium indicates the growth.

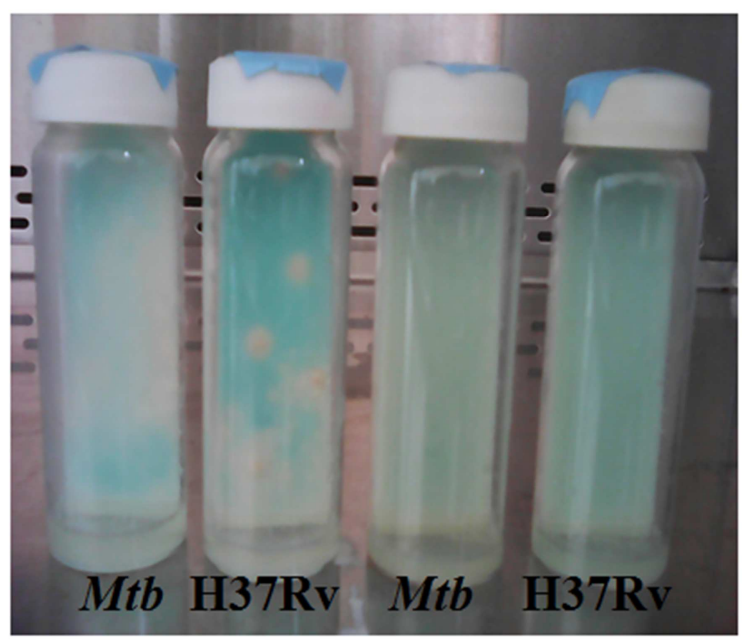

Figure 2. Tubes containing LJ showing of Mtb and H37Rv on the controls. From left to right: (-) controls with colonies and (+) controls without colonies (INZ) respectively.

Table 1. Anti-mycobacterial activity of the tested plant extracts with petroleum ether on of M. tuberculosis H37Rv and M. tuberculosis spp. at $20 \mu \mathrm{g} / \mathrm{mL}$ and 50 $\mu g / m L$

\begin{tabular}{|c|c|c|c|c|c|c|c|c|c|c|c|c|c|c|c|c|}
\hline \multirow{4}{*}{ Plant specimens and antibiotics } & \multicolumn{16}{|c|}{ Time in weeks } \\
\hline & \multicolumn{4}{|c|}{1} & \multicolumn{4}{|l|}{2} & \multicolumn{4}{|l|}{3} & \multicolumn{4}{|l|}{4} \\
\hline & \multicolumn{2}{|c|}{ H37Rv } & \multicolumn{2}{|c|}{ Mtb spp. } & \multicolumn{2}{|c|}{ H37Rv } & \multicolumn{2}{|c|}{ Mtb spp. } & \multicolumn{2}{|c|}{ H37Rv } & \multicolumn{2}{|c|}{ Mtb spp. } & \multicolumn{2}{|c|}{ H37Rv } & \multicolumn{2}{|c|}{ Mtb spp. } \\
\hline & $\mathbf{a}$ & b & $\mathbf{a}$ & b & $\mathbf{a}$ & b & $\mathbf{a}$ & b & $\mathbf{a}$ & $\mathbf{b}$ & $\mathbf{a}$ & b & $\mathbf{a}$ & b & $\mathbf{a}$ & B \\
\hline Terminalia ivorensis & - & - & - & - & - & - & - & - & - & - & - & - & - & - & - & - \\
\hline Carapa procera & - & - & - & - & - & - & - & - & - & - & - & - & - & - & - & - \\
\hline Fagara macrophylla & - & - & - & - & - & - & - & - & - & - & - & - & - & - & - & - \\
\hline Anacardium occidentale & - & - & - & - & - & - & - & - & - & - & - & - & - & - & + & \pm \\
\hline Ficus spp. & - & - & - & - & - & - & - & - & - & - & - & - & - & - & - & - \\
\hline Drepanoalpha ${ }^{\circledR}$ & - & - & - & - & - & - & - & - & - & - & - & - & - & - & - & - \\
\hline Rifampicin & - & - & - & - & - & - & - & - & - & - & - & - & - & - & - & - \\
\hline Isoniazid & - & - & - & - & - & - & - & - & - & - & - & - & - & - & - & - \\
\hline Ethambutol & - & - & - & - & - & - & - & - & - & - & - & - & - & - & - & - \\
\hline (-) control & - & - & - & - & - & - & \pm & \pm & - & - & + & + & - & - & + & + \\
\hline
\end{tabular}


Table 1. Continued.

\begin{tabular}{|c|c|c|c|c|c|c|c|c|c|c|c|c|c|c|c|c|}
\hline \multirow{4}{*}{$\begin{array}{l}\text { Plant specimens and } \\
\text { antibiotics }\end{array}$} & \multicolumn{16}{|c|}{ Time in weeks } \\
\hline & \multicolumn{4}{|l|}{5} & \multicolumn{4}{|l|}{6} & \multicolumn{4}{|l|}{7} & \multicolumn{4}{|l|}{8} \\
\hline & \multicolumn{2}{|c|}{ H37Rv } & \multicolumn{2}{|c|}{ Mtb spp. } & \multicolumn{2}{|c|}{ H37Rv } & \multicolumn{2}{|c|}{ Mtb spp. } & \multicolumn{2}{|c|}{ H37Rv } & \multicolumn{2}{|c|}{ Mtb spp. } & \multicolumn{2}{|c|}{ H37Rv } & \multicolumn{2}{|c|}{ Mtb spp. } \\
\hline & $\mathbf{a}$ & b & $\mathbf{a}$ & $\mathbf{b}$ & $\mathbf{a}$ & b & $\mathbf{a}$ & b & $\mathbf{a}$ & b & $\mathbf{a}$ & b & $\mathbf{a}$ & b & $\mathbf{a}$ & b \\
\hline Terminalia ivorensis & - & - & - & - & - & - & - & - & \pm & \pm & - & - & \pm & \pm & - & - \\
\hline Carapa procera & - & - & - & - & - & - & - & - & \pm & \pm & - & - & \pm & \pm & - & - \\
\hline Fagara macrophylla & - & - & - & - & - & - & - & - & \pm & \pm & - & - & \pm & \pm & - & - \\
\hline Anacardium occidentale & - & - & + & + & - & - & + & + & \pm & \pm & + & + & \pm & \pm & + & + \\
\hline Ficus spp. & - & - & - & - & - & - & - & - & \pm & \pm & - & - & \pm & \pm & - & - \\
\hline Drepanoalpha ${ }^{\circledR}$ & - & - & - & - & - & - & - & - & \pm & \pm & - & - & \pm & \pm & - & - \\
\hline Rifampicin & - & - & - & - & - & - & - & - & - & - & - & - & - & - & - & - \\
\hline Isoniazid & - & - & - & - & - & - & - & - & - & - & - & - & - & - & - & - \\
\hline Ethambutol & - & - & - & - & - & - & - & - & - & - & - & - & - & - & - & - \\
\hline (-) control & + & + & + & + & + & + & + & + & + & + & + & + & + & + & + & + \\
\hline
\end{tabular}

Legend: a: $20 \mu \mathrm{g} / \mathrm{mL}$, b: $50 \mu \mathrm{g} / \mathrm{mL},(-)$ : Negative, +: high growth, \pm : moderate growth, -: no growth, Mtb: M. tuberculosis

Table 2. Anti-mycobacterial activity of the tested plant extracts with ethyl acetate on M. tuberculosis H37Rv and M. tuberculosis spp. on at $20 \mu \mathrm{g} / \mathrm{mL}$ and 50 $\mu g / m L$

\begin{tabular}{|c|c|c|c|c|c|c|c|c|c|c|c|c|c|c|c|c|}
\hline \multirow{4}{*}{$\begin{array}{l}\text { Plant specimens and } \\
\text { antibiotics }\end{array}$} & \multicolumn{16}{|c|}{ Time in weeks } \\
\hline & \multicolumn{4}{|l|}{1} & \multicolumn{4}{|l|}{2} & \multicolumn{4}{|l|}{3} & \multicolumn{4}{|l|}{4} \\
\hline & \multicolumn{2}{|c|}{ H37Rv } & \multicolumn{2}{|c|}{ Mtb spp. } & \multicolumn{2}{|c|}{ H37Rv } & \multicolumn{2}{|c|}{ Mtb spp. } & \multicolumn{2}{|c|}{ H37Rv } & \multicolumn{2}{|c|}{ Mtb spp. } & \multicolumn{2}{|c|}{ H37Rv } & \multicolumn{2}{|c|}{ Mtb spp. } \\
\hline & $\mathbf{a}$ & $\mathbf{b}$ & $\mathbf{a}$ & b & $\mathbf{a}$ & $\mathbf{b}$ & $\mathbf{a}$ & $\mathbf{b}$ & $\mathbf{a}$ & b & $\mathbf{a}$ & $\mathbf{b}$ & $\mathbf{a}$ & b & $\mathbf{a}$ & b \\
\hline Terminalia ivorensis & - & - & - & - & - & - & - & - & - & - & + & \pm & - & - & + & + \\
\hline Carapa procera & - & - & - & - & - & - & - & - & - & - & - & - & - & - & - & - \\
\hline Fagara macrophylla & - & - & - & - & - & - & - & - & - & - & + & + & - & - & + & + \\
\hline Anacardium occidentale & - & - & - & - & - & - & - & - & - & - & + & + & - & - & + & + \\
\hline Ficus spp. & - & - & - & - & - & - & - & - & - & - & + & + & - & - & + & + \\
\hline Drepanoalpha ${ }^{\circledR}$ & - & - & - & - & - & - & - & - & - & - & + & + & \pm & - & + & + \\
\hline Rifampicin & - & - & - & - & - & - & - & - & - & - & - & - & - & - & - & - \\
\hline Isoniazid & - & - & - & - & - & - & - & - & - & - & - & - & - & - & - & - \\
\hline Ethambutol & - & - & - & - & - & - & - & - & - & - & - & - & - & - & - & - \\
\hline (-) control & - & - & - & - & - & - & \pm & \pm & - & - & + & + & - & - & + & + \\
\hline
\end{tabular}

Table 2. Continued.

\begin{tabular}{|c|c|c|c|c|c|c|c|c|c|c|c|c|c|c|c|c|}
\hline \multirow{4}{*}{$\begin{array}{l}\text { Plant specimens and } \\
\text { antibiotics }\end{array}$} & \multicolumn{16}{|c|}{ Time in weeks } \\
\hline & \multicolumn{4}{|l|}{5} & \multicolumn{4}{|l|}{6} & \multicolumn{4}{|l|}{7} & \multicolumn{4}{|l|}{8} \\
\hline & \multicolumn{2}{|c|}{ H37Rv } & \multicolumn{2}{|c|}{ Mtb spp. } & \multicolumn{2}{|c|}{ H37Rv } & \multicolumn{2}{|c|}{ Mtb spp. } & \multicolumn{2}{|c|}{ H37Rv } & \multicolumn{2}{|c|}{ Mtb spp. } & \multicolumn{2}{|c|}{ H37Rv } & \multicolumn{2}{|c|}{ Mtb spp. } \\
\hline & $\mathbf{a}$ & $\mathbf{b}$ & $\mathbf{a}$ & $\mathbf{b}$ & $\mathbf{a}$ & $\mathbf{b}$ & $\mathbf{a}$ & b & $\mathbf{a}$ & b & $\mathbf{a}$ & b & $\mathbf{a}$ & b & $\mathbf{a}$ & $\mathbf{b}$ \\
\hline Terminalia ivorensis & \pm & \pm & + & + & \pm & \pm & + & + & \pm & \pm & + & + & \pm & \pm & + & + \\
\hline Carapa procera & - & - & - & - & - & - & - & - & - & - & + & + & - & - & + & + \\
\hline Fagara macrophylla & - & - & + & + & - & - & + & + & - & - & + & + & - & - & + & + \\
\hline Anacardium occidentale & - & - & + & + & - & - & + & + & - & - & + & + & - & - & + & + \\
\hline Ficus spp. & - & - & + & + & - & - & + & + & - & - & + & + & - & - & + & + \\
\hline Drepanoalpha ${ }^{\circledR}$ & \pm & \pm & + & + & \pm & \pm & + & + & \pm & \pm & + & + & \pm & \pm & + & + \\
\hline Rifampicin & - & - & - & - & - & - & - & - & - & - & - & - & - & - & - & - \\
\hline Isoniazid & - & - & - & - & - & - & - & - & - & - & - & - & - & - & - & - \\
\hline Ethambutol & - & - & - & - & - & - & - & - & - & - & - & - & - & - & - & - \\
\hline (-) control & + & + & + & + & + & + & + & + & + & + & + & + & + & + & + & + \\
\hline
\end{tabular}

Legend: a: $20 \mu \mathrm{g} / \mathrm{mL}$, b: $50 \mu \mathrm{g} / \mathrm{mL},(-)$ : Negative, +: high growth, \pm : moderate growth, -: no growth, Mtb: M. tuberculosis 
Table 3. Anti-mycobacterial activity of the tested plant extracts with methanol on M. tuberculosis H37Rv and M. tuberculosis spp. at $20 \mu \mathrm{g} / \mathrm{mL}$ and $50 \mu \mathrm{g} / \mathrm{mL}$.

\begin{tabular}{|c|c|c|c|c|c|c|c|c|c|c|c|c|c|c|c|c|}
\hline \multirow{4}{*}{$\begin{array}{l}\text { Plant specimens and } \\
\text { antibiotics }\end{array}$} & \multicolumn{16}{|c|}{ Time in weeks } \\
\hline & \multicolumn{4}{|c|}{1} & \multicolumn{4}{|c|}{2} & \multicolumn{4}{|l|}{3} & \multicolumn{4}{|l|}{4} \\
\hline & \multicolumn{2}{|c|}{ H37Rv } & \multicolumn{2}{|c|}{ Mtb } & \multicolumn{2}{|c|}{ H37Rv } & \multicolumn{2}{|c|}{ Mtb } & \multicolumn{2}{|c|}{ H37Rv } & \multicolumn{2}{|c|}{ Mtb } & \multicolumn{2}{|c|}{ H37Rv } & \multicolumn{2}{|c|}{ Mtb } \\
\hline & $\mathbf{a}$ & b & $\mathbf{a}$ & b & $\mathbf{a}$ & b & $\mathbf{a}$ & $\mathbf{b}$ & $\mathbf{a}$ & b & $\mathbf{a}$ & b & $\mathbf{a}$ & $\mathbf{b}$ & $\mathbf{a}$ & b \\
\hline Terminalia ivorensis & - & - & - & - & - & - & - & - & - & - & - & - & - & - & + & \pm \\
\hline Carapa procera & - & - & - & - & - & - & - & - & - & - & - & - & - & - & + & \pm \\
\hline Fagara macrophylla & - & - & - & - & - & - & - & - & - & - & - & - & - & - & \pm & \pm \\
\hline Ficus spp. & - & - & - & - & - & - & - & - & - & - & - & - & - & - & \pm & \pm \\
\hline Drepanoalpha ${ }^{\circledR}$ & - & - & - & - & - & - & - & - & - & - & - & - & - & - & - & - \\
\hline Rifampicin & - & - & - & - & - & - & - & - & - & - & - & - & - & - & - & - \\
\hline Isoniazid & - & - & - & - & - & - & - & - & - & - & - & - & - & - & - & - \\
\hline Ethambutol & - & - & - & - & - & - & - & - & - & - & - & - & - & - & - & - \\
\hline (-) control & - & - & - & - & - & - & \pm & \pm & - & - & + & + & - & - & + & + \\
\hline
\end{tabular}

Table 3. Continued.

\begin{tabular}{|c|c|c|c|c|c|c|c|c|c|c|c|c|c|c|c|c|}
\hline \multirow{4}{*}{$\begin{array}{l}\text { Plant specimens and } \\
\text { antibiotics }\end{array}$} & \multicolumn{16}{|c|}{ Time in weeks } \\
\hline & \multicolumn{4}{|l|}{5} & \multicolumn{4}{|l|}{6} & \multicolumn{4}{|l|}{7} & \multicolumn{4}{|l|}{8} \\
\hline & \multicolumn{2}{|c|}{ H37Rv } & \multicolumn{2}{|c|}{ Mtb } & \multicolumn{2}{|c|}{ H37Rv } & \multicolumn{2}{|c|}{ Mtb } & \multicolumn{2}{|c|}{ H37Rv } & \multicolumn{2}{|c|}{ Mtb } & \multicolumn{2}{|c|}{ H37Rv } & \multicolumn{2}{|c|}{ Mtb } \\
\hline & $\mathbf{a}$ & $\mathbf{b}$ & $\mathbf{a}$ & $\mathbf{b}$ & $\mathbf{a}$ & b & $\mathbf{a}$ & $\mathbf{b}$ & $\mathbf{a}$ & $\mathbf{b}$ & $\mathbf{a}$ & b & $\mathbf{a}$ & b & $\mathbf{a}$ & b \\
\hline Terminalia ivorensis & - & - & + & + & - & - & + & + & - & - & + & + & - & - & + & + \\
\hline Carapa procera & - & - & + & + & - & - & + & + & - & - & + & + & - & - & + & + \\
\hline Fagara macrophylla & - & - & + & + & - & - & + & + & - & - & + & + & - & - & + & + \\
\hline Ficus spp. & - & - & + & + & - & - & + & + & - & - & + & + & - & - & + & + \\
\hline Drepanoalpha $\mathbb{}$ & - & - & - & - & - & - & - & - & - & - & + & + & - & - & + & + \\
\hline Rifampicin & - & - & - & - & - & - & - & - & - & - & - & - & - & - & - & - \\
\hline Isoniazid & - & - & - & - & - & - & - & - & - & - & - & - & - & - & - & - \\
\hline Ethambutol & - & - & - & - & - & - & - & - & - & - & - & - & - & - & - & - \\
\hline (-) control & + & + & + & + & + & + & + & + & + & + & + & + & + & + & + & + \\
\hline
\end{tabular}

Legend: a: $20 \mu \mathrm{g} / \mathrm{mL}$, b: $50 \mu \mathrm{g} / \mathrm{mL},(-)$ : Negative, +: high growth, \pm : moderate growth, -: no growth, Mtb: M. tuberculosis

M. tuberculosis $\mathrm{H} 37 \mathrm{Rv}$ showed no growth up to 6 weeks when cultured in the medium containing Ficus spp. extracted with petroleum ether (table 1). A moderate growth was observed at both concentrations $(20 \mu \mathrm{g} / \mathrm{mL}$ and $50 \mu \mathrm{g} / \mathrm{mL})$ for all the remaining extracts. While for M. tuberculosis spp., no growth was recorded with $T$. ivorensis, C. procera, $F$. macrophylla, Ficus spp. and Drepanoalpha ${ }^{\circledR}$. There was a moderate growth at $50 \mu \mathrm{g} / \mathrm{mL}$ and a high growth at $20 \mu \mathrm{g} / \mathrm{mL}$ on $A$. occidentale which increased till the end of the experiment.

After 4 weeks, a high growth was recorded in the medium containing T. ivorensis, F. macrophylla, A. occidentale, Ficus spp. extracted with ethyl acetate (table 2) at both concentrations when cultured with $M$. tuberculosis except for T. ivorensis a moderate growth was recorded at $50 \mu \mathrm{g} / \mathrm{ml}$ the same week. At the seventh week, growth was recorded in the medium cultured with M. tuberculosis containing C. procera. On the other side, a moderate growth was observed at the fourth week in the medium cultured with $M$. tuberculosis H37Rv having Drepanoalpha ${ }^{\circledR}$ at $20 \mu \mathrm{g} / \mathrm{ml}$ and at both concentrations at the fifth week and $T$. ivorensis at the fifth week at both concentrations while no growth was recorded in tubes containing C. procera, F. macrophylla, A. occidentale and Ficus spp.

From table 3, in tubes cultured with Mtb H37Rv no growth was recorded for the plants extracted with methanol i.e. there was a strong activity of these extracts for all the duration of the experiments. Whilst when cultured with $\mathrm{Mtb}$, a moderate growth was recorded in tubes containing F. macrophylla and Ficus spp at both concentrations but for tubes containing $T$. ivorensis and C. procera the growth was moderate at 50 $\mu \mathrm{g} / \mathrm{ml}$ and high at $20 \mu \mathrm{g} / \mathrm{ml}$ At the seventh week, a high growth was recorded inside tubes containing Drepanoalpha ${ }^{\circledR}$ at both concentrations $(20 \mu \mathrm{g} / \mathrm{ml}$ and $50 \mu \mathrm{g} / \mathrm{ml})$ while a moderate growth was recorded in the medium containing $A$. occidentale at both concentrations as well and a high growth was observed at the last week.

\subsubsection{Phytochemical Screening}

The phytochemical screening was performed using colored and precipitation reactions. Different chemicals are given in the following table. 
Table 4. Phytochemical screening results thru colored and precipitation reactions.

\begin{tabular}{lllllll}
\hline Phytochemicals & Terminalia ivorensis & Carapa procera & Fagara macrophylla & Anacardium occidentale & Ficus spp. & Drepanoalpha $® \circledR ~$ \\
\hline Flavonoids & + & + & + & + & + & + \\
Anthocyanins & - & + & + & + & + & + \\
Tannins & + & + & + & + & + & + \\
Leucoanthocyanins & + & + & + & + & + & + \\
Bound quinones & + & - & + & + & - & + \\
Alkaloids & + & + & + & + & + & + \\
Saponins & + & + & + & + & + & + \\
Polyphenols & + & + & + & + & + \\
\hline
\end{tabular}

Legengd: +: presence, -: absence

Flavonoids, tannins, leucoanthocyanins, alkaloids, saponins and polyphenols were present in all extracts while anthocyanins and bound quinones were absent in $T$. ivoriensis, C. procera and Ficus spp. respectively.

\subsection{Discussion}

Tuberculosis (TB) is still a serious illness and a serious public health problem with medical, sociological and economic consequences that has a fatal end in more than $50 \%$ of untreated cases [24] and the importance of rapid availability of $M$. tuberculosis drug resistance results is universally acknowledged due to the problem of resistance [25], henceforth finding healing properties in plants is an ancient idea that is coming up again [26]. In the current study, the focus was to assess the anti-mycobacterial activity of T. ivorensis, C. procera, F. macrophylla, A. occidentale, Ficus spp. as medicinal plants and of Drepanoalpha ${ }^{\circledR}$ (a Congolese phytomedicine used against Sickle Cell Anemia) using a qualitative approach with different solvents notably petroleum ether, ethyl acetate and methanol on LJ medium.

Several reports have documented the anti-mycobacterial properties of Terminalia species but only a few species from this genus have been explored for their anti-mycobacterial constituents. T. ivorensis was also tested for its trypanocidal, anti-inflammatory, anti-arthritis and antibacterial properties, as well as for the treatment of syphilis among the Jukuns [2729]. Though no study indicated the anti-mycobacterial activity of $T$. ivorensis yet, findings of the present study confirm its anti-mycobacterial activity. Nevertheless, it has been confirmed with other species of Terminalia genus such as T. superba [30], T. serica [31].

Carapa procera displayed a good activity and it has been proven to possess a lot of virtues such as anti-malarial with C. guianensis [32], and larvicidal [33]. Bishola [34] reported the antisickling and radical scavenging activity of the bark of this plant.-There is limited information regarding the antimycobacterial activity of $C$. procera or even in other species of the same genus. Olugbuyiro et al., [35], reported the antimycobacterial activity of the methanolic extract of $A$. occidentale using quantitative approach (BACTEC). This report goes along with the current one, though a qualitative approach was used whereby the absence of growth was regarded as effective. Other uses have been reported by Onasanwo et al., [36] stating that the leaves $A$. occidentale have high potent analgesic and anti-inflammatory properties. F. macrophylla has been proven useful in the treatment of hypertension, colds and stomach-ache, fever, malaria and cancers [30]. Ficus spp. and Drepanoalpha ${ }^{\circledR}$ also showed a good anti-mycobacterial activity for all the extracts.

Using LJ medium, the activity was quite good for the methanol and petroleum ether extracts though there was an invasive growth in the ethyl acetate extract with moderate growth for H37Rv but with high growth with M. tuberculosis spp. This finding differs from other studies that proved that there was inhibition of $M$. tuberculosis and other types of Mycobacteria using the LJ medium but at $1 \mathrm{mg} / \mathrm{mL}$ of the extracts or more [22]. In the same framework, Radji et al. [37] reported the in vitro anti-mycobacterial activity of five selected plants in Indonesia against M. tuberculosis H37Rv and MDR strain using a quantitative LJ proportion method. All extracts of these five plants showed a good activity against $M$. tuberculosis $\mathrm{H} 37 \mathrm{Rv}$ strain and MDR strain with the proportion inhibition of $5 \mathrm{mg} / \mathrm{mL}$ of aqueous extract. This scenario can be due to the low concentration of the extracts into the medium, the nature of the compounds contained in the plants, the nature of the solvent used for the extraction or the time allocated for the inspissation as it was 45 minutes to 60 minutes for the current study. Considering that it is a heated medium, many components of the extracts can evaporate or lose their activity at a certain temperature. Another thought is the part of the plant used for the experiment, the geographical origin of the plant, the nature of the soil where the plant was collected. In the current study, extracts that showed anti-mycobacterial activity such as $T$. ivorensis, C. procera, F. macrophylla and Drepanoalpha ${ }^{\circledR}$ which are less reported in the literature, need further investigations in order to confirm this activity in vitro and in vivo using an animal model. Biochemical profiles of plants collected at different moments and locations may vary greatly. Many phytochemicals were identified in different plants used, thus there is need of identifying and characterizing the molecule or molecules that really possess the anti-mycobacterial activity.

Phytochemicals in plant extracts can act as leads in providing useful scaffolds or templates, for the development of new antitubercular drugs [21], as the genome sequence of $M$. tuberculosis has been established. Promising lead compounds from plant sources may also act on newer targets and thus may play a crucial role in the development of new generation 
antitubercular drugs [22]. Findings from the current study displayed the presence of flavonoids, tannins, leucoanthocyanins, alkaloids, saponins and polyphenols all extracts but anthocyanins and bound quinones were found absent in T. ivoriensis, C. procera and Ficus spp. respectively. It should be noted that these phytochemicals are found in leaves for the current study. Several studies reported the presence of tannins, flavonoids, saponins, glycosides, alkaloids, coumarins, quinones, anthocyanins, leucoanthocyanins, triterpenes (steroids), total polyphenols, anthraquinones and oxalates in different parts of the plants [32-33, 38-39]. Mpiana, et al. [40], reported the presence of phenolic compounds such as anthocyanins, leucoanthocyanins, quinones, tannins and flavonoids, terpenoids and alkaloids as well organic acids in Drepanoalpha ${ }^{\circledR}$.

These phytochemicals precisely alkaloids, flavonoids and tannins have been proven to possess anti-mycobacterial activity [12]. Differences on results might be due to solvents used, the used part of the plant and different methods of extraction as well as geographic variation, climate, nature of the soil, harvest time. All these factors might have effects on the composition and phytochemical diversity of medicinal plants [12] [41]. Nevertheless, this variation does not justify the genetic variation of the species and the chemical diversity in nature is based on biological and geographical diversity [21].

\section{Conclusion}

Most of the plants selected showed activity against Mycobacterium tuberculosis, hence the reason as to why they are commonly used by herbalists for treatment of various diseases. The results from the investigation revealed that most of the medicinal plants contain pharmacologically active substances that are anti-mycobacterial. The presence of phytochemicals known to be of medicinal importance pointed out a possible source for anti-mycobacterial agents to address the problem of MDR-TB and XDR-TB. The findings of this study provide a partial support to the use of these plants in the management of various infectious diseases. Further studies are needed in order to verify the in vivo activity using animal models and proceed with clinical trials to allow their use in the management of this disease in the community. As well as to carry out the minimum inhibitory concentration and the minimum bactericidal concentration of these extracts then proceed with the isolation, identification, characterization and structure elucidation of the bioactive compounds and the screening of these compounds against different mycobacterial strains.

\section{Acknowledgements}

The authors are indebted to BEBUC Scholarship System (Bourse d'Excellence Bringmann aux Universités Congolaises), the Else-Kroener-Fresenius Stiftung, the Holger-Pöhlmann-Foundation (Deutschland) and INTRA ACP Academic Mobility Scheme for their financial support to Gédéon N. Bongo to carry out this research. A sincere word of gratitude to Prof. Dominic Kambarage (Sokoine University of Agriculture) for his particular contribution for our blossoming as well as to Pendo Maula for her technical assistance. To Mr Jean-Pierre Mukendi Kambala for his encouragements and his involvement in the revision of this manuscript. This paper is dedicated in memoriam of Dr. Huruma N. Tuntufye ${ }^{\ddagger}$, who has passed away after the submission of this work and before this publication.

\section{References}

[1] Vikrant, A. A Review on Anti-Tubercular Plants. International Journal of PharmTech Research, 2011, 3(2):872-880.

[2] Lwilla, F., Schellenberg, D., Masanja, H., Acosta, C., Galindo, C., Aponte, J., Egwaga, S., Njako, B., Ascaso, C., Tanner, M. and Alonso, P. Evaluation of efficacy of community-based vs. institutional-based direct observed short-course treatment for the control of tuberculosis in Kilombero district, Tanzania. Tropical Medicine and International Health, 2003, 8(3):204210 .

[3] Muna M. B. and Fauzia R. E. G. Antibacterial Activity of Medicinal Aqueous Plant Extracts against Mycobacterium tuberculosis. Malaysian Journal of Microbiology, 2012, 8(3): 203-206.

[4] Gizachew, E. Y., Giday, M. and Teklehaymanot, T. Antimycobacterial Activities of Selected Ethiopian Traditional Medicinal plants used for treatment of symptoms of Tuberculosis. Global Advanced Research Journal of Medicinal Plants, 2013, 2(2):022-029.

[5] Ngbolua, K. N., Gédéon, N. B., Masengo, C. A., Djolu, R. D., Pius, T. M., Virima, M., Lassa, K. and Huruma N. T. Ethnobotanical survey and Ecological study of Plants resources used in Folk medicine to treat symptoms of Tuberculosis in Kinshasa City, Democratic Republic of the Congo. Journal of Modern Drug Discovery and Drug Delivery Research, 2014, 1(4):1-6.

[6] World Health Organization report (WHO). Global Tuberculosis. WHO Geneva, Switzerland, 2014, 171pp.

[7] Wynne, A., Jhangri, S. G., Richter, S., Alibhai, A., Rubaale, T., and Kipp, W. Tuberculosis in the era of infection with the human immunodeficiency virus: assessment and comparison of community knowledge of both infections in rural Uganda. BioMed Central International Health Human Rights, 2012, 12:36.

[8] Hudson, A., Imamura, T., Gutteridge, W., Kanyok, T. and Nunn, P. The current anti-TB drug research and development pipeline. Special Programme for Research and Training in Tropical Disease, 2003, 48pp.

[9] Kaswa, K. M., Bisuta, S., Kabuya, G., Lunguya, O., Ndongosieme, A., Muyembe, J. J., Van Deun, A. and Boelaert, M. (2014). Multi Drug Resistant Tuberculosis in Mosango, a Rural Area in the Democratic Republic of Congo. Plos One, 9(4):1-4.

[10] Ministère de la Santé Publique. Module de formation: Prise en charge de la co-infection VIH-Tuberculose au niveau du centre de santé (Niveau B). Programme National de Lutte contre le VIH et les IST, République Démocratique du Congo, 2008a, $58 \mathrm{pp}$. 
[11] Ministère de la Santé Publique. Guide de prise en charge de la tuberculose PATI 4 (Health care guide of Tuberculosis). Edition 2008, Programme National de Lutte contre le VIH (HIV) et les IST (TSI), République Démocratique du Congo, 2008b, $97 \mathrm{pp}$

[12] Bunalema, L. Anti-mycobacterial activity and acute toxicity of Erythrina abyssinica, Cryptolepis sanguinolenta and Solanum incanum. Unpublished Dissertation for Award of MSc Degree at the University of Makerere, Kampala, Uganda, 2010, 53pp.

[13] Molly, A., James, J., Misra, S. C., Sagadevan, L. D. M., Veettil, A. K. T. and Thankamani, V. Anti-mycobacterial activity of the plant extracts of Alstonia scholaris. International Journal of Current Pharmaceutical Research, 2011, 4(1):40-42.

[14] Hosseini, M. S., Wright, A., Lambregts, C., Weezenbeck, V., Nunn, P., Watt, C. S., Williams, B. G. and Dye, C. Global incidence of multi-drug resistant tuberculosis. Journal of Infectious Diseases, 2006, 194: 479-485.

[15] Corbett, E. L., Watt, C. J., Walker, N., Maher, D., Williams, B. G., Raviglione, M. C. and Dye, C. The growing burden of tuberculosis. Global trends and interactions with the HIV Epidemic. Archives of Internal Medicine, 2003, 163:10091021.

[16] Cooke, G. J. Public Health Africa: A Report of the Center for Strategic \& International Studies (CSIS) Global Health Policy Center. CSIS, 2009, 16pp.

[17] Gandhi R. N., Nunn P., Dheda K., Schaaf H. S., Zignol M., Dick van Soolingen D. V., Jensen P. and Bayona J. Multidrug-resistant and extensively drug-resistant tuberculosis: a threat to global control of tuberculosis. The Lancet, 2010, 375: 1830-1843.

[18] Tijjani, M. B.; Bello, I. A.; Aliyu, A. B.; Olurishe, T.; Maidawa, S. M.; Habila, J. D. and Balogun, E. O. Phytochemical and antibacterial studies of root extract of Cochlospermum tinctorium A. rich. (Cochlospermaceae). Research Journal of Medicinal Plant, 2009, 3: 16-22.

[19] Mariita, M. R,. Callistus K. P. O. O., Oguge, O. N. and Paul O Okemo, O. P. Antitubercular and Phytochemical Investigation of Methanol Extracts of Medicinal Plants Used by the Samburu Community in Kenya. Tropical Journal of Pharmaceutical Research, 2010b, 9 (4): 379-385.

[20] Edeoga H. O., Okwu D. E. and Mbaebie B. O. Phytochemical constituents of some Nigerian medicinal plants. African Journal of Biotechnology, 2005, 4(7):685-688.

[21] Mativandlela, S. P. N. Antituberculosis activity of flavonoids from Galenia africana L. var. Africana. Unpublished Dissertation for award of $\mathrm{PhD}$ degree, at the Faculty of Natural and Agricultural Science, University of Pretoria, South Africa, 2009, 189pp.

[22] Mariita, M. R. Efficacy of medicinal plants used by communities around Lake Victoria region and The Samburu against Mycobacteria, selected bacteria and Candida albicans. Unpublished Dissertation for Award of MSc degree in the School of Pure and Applied Sciences, Kenyatta University, Nairobi, Kenya, 2010a, 139pp.

[23] Bukatuka F. C., Ngombe K. N., Mutwale K. P., Moni B. M., Makengo K. G., Pambu L. A., Bongo N. G., Mbombo M. P., Musuyu M. D., Maloueki U., Koto-te-Nyiwa Ngbolua and Mbemba F. T. Bioactivity and Nutritional Values of Some Dioscorea Species Traditionally Used as Medicinal Foods in
Bandundu, DR Congo. European Journal of Medicinal Plants, 2016, 14(1):1-11.

[24] Asres, K., Bucar, F., Edelsbrunner, S. Kartnig, T., Hoger, G., and Thiel, W. Investigations on antimicrobial activity of some Ethiopian medicinal plants. Phytotherapy Research, 2001, 15:323-326.

[25] Aktas, E. A., Yigit, N., Ayyildiz, A. and Bastopcu, A. Comparison of the Mycobacterium growth indicator tube method and the method of proportion for drug susceptibility testing of Mycobacterium tuberculosis. Eurasian Journal of Medicine, 2014, 46:96-101.

[26] Cowan, M. M. Plant products as antimicrobial agents. Clinical Microbiology Reviews, 1999, 12(4):564-582.

[27] Malcon, S. A. and Sofowora, E. A. Antimicrobial activity of selected Nigerian folk remedies and their constituent plants. Lloydia, 1969, 32:512-517.

[28] Iwu, M. M. and Anyawu, B. N. Anti-inflammatory and antiarthritic properties of Terminalia ivorensis. Filoterapia, 1982, $52: 25-34$.

[29] Agbedahunsi, M. J., Anao, I., Adewunmi, O. C., and Croft, L. S. Trypanocidal properties of Terminalia ivorensis A. Chev. (Combretaceae). African Journal Traditional, Complementary and Alternative Medicines, 2006, 3(2):51-56.

[30] Kuete, V., Sandjo, P. L., Mbaveng, T. A., Seukep, A. J., Ngadjui, T. B. and Efferth, T. Cytotoxicity of selected Cameroonian medicinal plants and Nauclea pobeguinii towards multi-factorial drug-resistant cancer cells. BioMed Central, Complementary and Alternative Medicine, 2015, 15:309.

[31] Eldeen, I. M. S. and Staden, V. J. Antimycobacterial activity of some trees used in South African traditional medicine. South African Journal of Botany, 2007, 73(2):248-251.

[32] Pereira, T. B., Rocha e Silva, F. L., Amorim, C. N. R., Melo, R. S. M., Zacardi de Souza, C. R., Eberlin, N. M., Lima, S. E., Vasconcellos, C. M. and Pohlit, M. A. In vitro and in vivo antimalarial activity of limonoids isolated from the residual seed biomass from Carapa guianensis (andiroba) oil production. Malaria Journal, 2014, 13:137.

[33] Missah, B. Larvicidal and anti-plasmodial constituents of Carapa procera DC. (Meliaceae) and Hyptis suaveolens L. POIT (Lamiaceae). Unpublished dissertation for the award of MSc degree, Department of Pharmacognosy Faculty of Pharmacy and Pharmaceutical Sciences, Kwaume Nkrumah University of Science and Technology: College of Health Sciences, Kumasi, Ghana, 2014, 100pp.

[34] Bishola, T. T. Etude phytochimique et détermination de quelques activités biologiques de Pentaclethra macrophylla Benth (Fabaceae), Carapa procera Decne (Meliaceae) et Garcinia punctata Decne (Clusiaceae) (Phytochemical screening and assessment of biological activities of Pentaclethra macrophylla Benth (Fabaceae), Carapa procera Decne (Meliaceae) and Garcinia punctata Decne (Clusiaceae)). Unpublished Dissertation for Award of BSc Degree at the University of Kinshasa, Kinshasa, DRC, 2013, 125pp.

[35] Olugbuyiro, A. O. J., Moody, O. J. and Hamann, M. T. Antiinfective potential of some medicinal plants used in SouthWest Nigeria. International Journal of Innovations in BioSciences, 2013, 3(3):104-110. 
[36] Onasanwo, S. A., Fabiyi, T. D., Oluwole, F. S. and Olaleye, S. B. Analgesic and anti-inflammatory properties of the leaf extracts of Anacardium occidentale in the laboratory rodents. Nigerian Journal of Physiological Sciences, 2012, 27(1):65-71.

[37] Radji, M., Kurniati M. and Kiranasari A. Comparative antimycobacterial activity of some Indonesian medicinal plants against multi-drug resistant Mycobacterium tuberculosis. Journal of Applied Pharmaceutical Science, 2015, 5(01): 019-022.

[38] Nwankwo, I. U. and Ukaegbu-Obi, K. M. Preliminary phytochemical screening and antibacterial activity of two Nigerian medicinal plants (Ficus asperifolia and Terminalis catappa). Journal of Medicinal Plant and Herbal Therapy, 2014, 2(2014):1-5.
[39] Ojezele, O. M. and Agunbiade, S. Phytochemical Constituents and Medicinal Properties of Different Extracts of Anacardium Occidentale and Psidium Guajava. Asian Journal of Biomedical and Pharmaceutical Sciences, 2013, 3(16):20-23.

[40] Mpiana, P. T., Ngbolua, K. N., Tshibangu, D. S. T., Mazasa, P. P., Gbolo, B. Z., Atibu, E. K., Kadima, J. N. and Kasali, F. M. In vitro Antisickling and Radical Scavenging Activities of a Polyherbal Formula (Drepanoalpha $\mathbb{R}($ ) in Sickle Cell Erythrocyte and Acute Toxicity Study in Wistar Albino Rats. European Journal of Medicinal Plants, 2014, 4(10):1251-1267.

[41] Gaya, C. H., Kawaka, J. F., Muchungi, A. and Ngeranwa, J. J. Variation of alkaloids in the Kenyan Zanthoxylum gilletii (De Wild Waterman). African Journal of Plant Science, 2013, 7(9):438-444. 